\title{
CONVIS: A tool enabling uninterrupted operation during refurbishments of complex buildings
}

\author{
Ugo Maria Coraglia \\ TU Wien, Austria, Sapienza University of Rome, \\ Italy \\ ugomaria.coraglia@uniroma1.it \\ Gabriel Wurzer \\ TU Wien, Austria \\ wurzer@iemar.tuwien.ac.at
}

\begin{abstract}
Clash Detection refers to the identification of geometrical overlaps within a Building Information Model (BIM). This paper seeks to extend the notion of overlapping to activities: Given a construction site within a building, we seek to find clashes between construction activities and occupant routines. Such a situation is often encountered in the context of refurbishments of complex buildings operating 24/7 (e.g. airports, train stations, hospitals, prisons). By finding the influence radii of adverse effects resulting from construction - i.e. dust, noise and vibrations, functions may be temporarily relocated in order to guarantee uninterrupted operation. Our tool CONVIS implements these simulation and scheduling aspects and seeks to provide a digital project plan for refurbishments in the said context.
\end{abstract}

Keywords: Complex Buildings, Construction Site, Simulation.

\section{Introduction}

During the renovation of complex buildings construction activities need to be separated from daily operation due to dust, noise and vibrations. Considering the concrete example of a hospital (Zhang et al. 2013), we observe that

- vibrations can make electronic instruments for monitoring patients unusable

- loud construction activities can cover a heart alarm in the ICU; sudden noises can furthermore be dangerous during surgery operations

- dust dispersion is dangerous - especially for patients at high risk for invasive Aspergillosis (D'Alessandro et al., 2007)

Separating daily operation from construction activities poses a scheduling and allocation problem which is hard to solve since no integrated planning tool exists. In our prototype implementation, we have thus implemented a common environment in which we are able to plan and visualise both aspects. Our tool CONVIS allows for Clash Detection between construction and work activities and takes the form of a digital project plan with a time-based view. As data basis, we use exported schemata coming from CAAD or BIM packages.

\section{Background}

Clash Detection has been dealt with mostly in the context BIM, either in a 3D (geometric) or 4D (geometric and time-based) view of a project (Azhar 2011). In that context, clashed have been characterized by their type (see Table 1) and classified according to possible resolution strategies (see Table 2). Both of these notions of Clash Detection are linked to the geometric side only. However, this results in an oversimplification if one considers the context of renovation or refurbishments of a complex structure (e.g. a healthcare building) which remains in operation during the construction period. Inside such buildings, it would be favourable to also consider clashes between construction activities and work routines, which in turn are based on stakeholders and technical elements serving daily work routines. Rather than considering construction activities as such, this work deals with their effects split up into the three categories noise, dust and vibrations.

Table 1: Geometrical Interference classification

\begin{tabular}{|l|l|}
\hline TYPE OF CLASH & DESCRIPTION \\
\hline Clashes betw een 2 or more elements. \\
\hline Clearance & $\begin{array}{l}\text { element A may/may not inters ect element B, } \\
\text { occurring at a low er dis tance than the } \\
\text { tolerance (e.g. Due to overheating two } \\
\text { elements mus t be placed at a determined } \\
\text { safety dis tance). }\end{array}$ \\
\hline Duplicate & $\begin{array}{l}\text { two elements have the s ame geometry and } \\
\text { are placed w ithin range of tolerance. If the } \\
\text { tolerance is zero, they occupy the same } \\
\text { position. }\end{array}$ \\
\hline
\end{tabular}

Considering these three categories requires a certain regulatory framework which may take its concrete form in either national or international law. For example, the European regulation states that exposure to noise should not exceed $87 \mathrm{~dB}$. In cases where sound levels exceed $80 \mathrm{~dB}$, sound 
insulation measures are obligatory (Directive 2003/10/CE). In previous legislation (UNI EN ISO 11690-1:1996), it was established that an exposure to more than $80 \mathrm{~dB}$ may last only for a few minutes. Similar regulations also exist for the respiration of dust (e.g. CFR 29 1926.55) and the acceptable levels of vibrations (e.g. ISO 4866:2010).

Table 2: Colour classification of clash detection

\begin{tabular}{|l|l|l|}
\hline TYPE OF CLASH & COL OUR & DESCRIPTION \\
\hline New & red & $\begin{array}{l}\text { interference identified for the first } \\
\text { time through a new test. }\end{array}$ \\
\hline Active & orange & $\begin{array}{l}\text { interference identified in a } \\
\text { previous test, not yet res olved. }\end{array}$ \\
\hline Reviewed & blue & $\begin{array}{l}\text { previous ly identified interference, } \\
\text { manually tagged as detected. }\end{array}$ \\
\hline Approved & green & $\begin{array}{l}\text { previous ly identified interference, } \\
\text { manually approved. }\end{array}$ \\
\hline Res olved & yellow & $\begin{array}{l}\text { previously identified interference } \\
\text { now resolved. }\end{array}$ \\
\hline
\end{tabular}

The risk of noise exposure is real and for this reason the World Health Organization (WHO) recommends a maximum noise level e.g. for hospital environments in the range of $45 \mathrm{~dB}$ (but not exceeding $80 \mathrm{~dB}$ which is the said maximum; see Castro et al. 2013). However, some analysis highlight that the level of noise recorded exceed these recommended levels: In Austrian hospitals, for example, a level of $65 \mathrm{~dB}$ has been observed, while Spanish hospitals may have as much as $55 \mathrm{~dB}$ in practice (see again Castro et al. 2013).

The study of maximum acceptable noise levels has arguably as much to do with science as with subjective assessment of the context (Choiniere 2010); In Italy, current regulations thus state acceptable noise levels according to functions, from 30 $\mathrm{dB}$ (Hospital rooms) to $40 \mathrm{~dB}$ (General service areas) (see Table 3), in accordance with UNI 8199-1998 and UNI 81992016 (Uguccioni, G. 2005). Likewise, diversification trends are also in effect for dust and vibrations: The Canadian Centre for Infectious Disease Prevention and Control, for example, has proposed a proactive approach regarding the dust particle risk resulting from a classification system, which frames the construction site activities within the hospitals in 4 specific categories (from non-invasive activities to significant demolition and reconstruction [after Moscato et al. 2007]; see Table 4).

A tool supporting actual construction work must thus be fully customizable to individual standards, which is why we have made our implementation parameterisable with regards to acceptable levels for dust, noise and vibration.
Table 3: Noise limit for hospital environments

\begin{tabular}{|l|c|}
\multicolumn{1}{|c|}{ ENV IRONMENT } & NOISE LIMIT \\
\hline Hos pital rooms & $30 \mathrm{~dB}(\mathrm{~A})$ \\
\hline Wards & $40 \mathrm{~dB}(\mathrm{~A})$ \\
\hline Operating theatres & $35 \mathrm{~dB}(\mathrm{~A})$ \\
\hline Connection zones & $40 \mathrm{~dB}(\mathrm{~A})$ \\
\hline V is itors area & $40 \mathrm{~dB}(\mathrm{~A})$ \\
\hline General service areas & $40 \mathrm{~dB}(\mathrm{~A})$ \\
\hline
\end{tabular}

Our tool uses the paradigm of a digital project plan. It shows a time-dependent visualization of construction activities and their effects. Similar efforts have been previously made by Trento et al. (2014), who have linked construction entities and activities for hazard prediction. However, the authors are more geared towards representation of safety rules within BIM rather than simulation of effects (as in our case). On the other hand, they are performing their case study within a BIM environment to which our approach is simply a client (export of schemata from CAAD or BIM into our tool). Conceptually, our approach is part of the movement towards BIM lifecycle models: As operation and refurbishment are happening at the same time, it makes sense to think about a common data basis (see e.g. the U.S. Healthcare BIM Consortium - HBM - which supports the increase in data interoperability for the Facility Life Cycle Management, as reported by Linehan 2013).

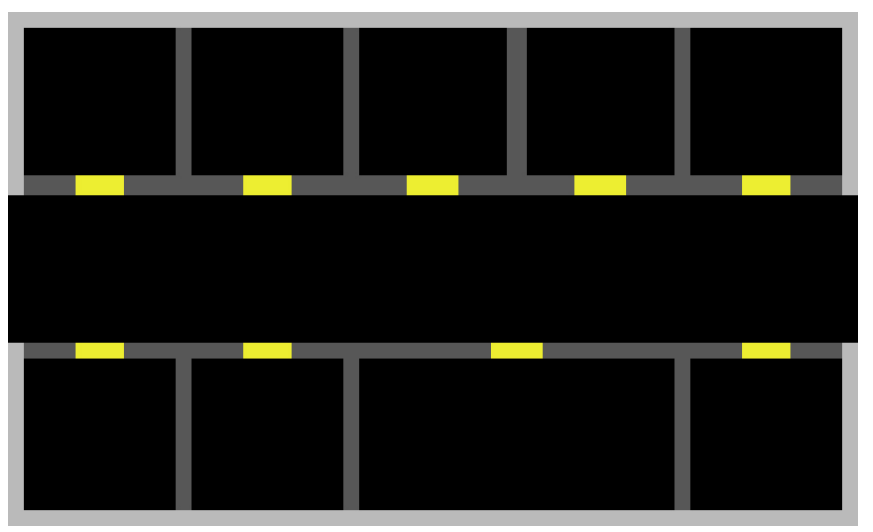

Figure 1: schema of ward and its characteristics (e.g. materials, sound insulation capacity)

\section{Methodology}

Our main aim is to reduce the negative impact of construction activities on the surrounding building environment. In order to be applicable even for early stages of design, we use schematics (room boundaries as opposed to full-fledged representation such as in IFC), on top of which we annotate planned activities (construction; regular work routines) in a 
time-based manner. The influence between these two types of activities is furthermore simulated (particle-based noise, dust and vibration simulation) and brought to the attention of the tool user via visualization. Our workflow includes the following steps:
- Export of a spatial model to schematics: A BIM typically acts as a spatial database stating the location of walls and entrances plus their composition (material). We export the plans of rooms as bitmaps and process them within a graphics software (wall and door type/material encoded as colours; see Figure 1).

Table 4: Risk matrix of construction activities

\begin{tabular}{|c|c|c|}
\hline $\begin{array}{c}\text { TYPES OF } \\
\text { CONSTRUCTION } \\
\text { ACTIVITIES }\end{array}$ & EXAMPLES OF CONSTRUCTION ACTIVITIES & LEVEL OF RISK \\
\hline $\begin{array}{l}\text { TYPE A } \\
\text { Ins pection and non-invas ive } \\
\text { activity, w ithout generating } \\
\text { dust and drilling w alls }\end{array}$ & $\begin{array}{l}\text { Removal of fals e ceiling panels for vis ual ins pection; } \\
\text { Painting; } \\
\text { Re-paneling walls; } \\
\text { S mall electrical w ork; } \\
\text { S mall interventions on ventilation or terminal hydraulic Sys tems that } \\
\text { require no more than } 15 \text { minutes. }\end{array}$ & LOW \\
\hline $\begin{array}{l}\text { TYPE B } \\
\text { S mall scale and duration } \\
\text { activities, generating s mall } \\
\text { amounts of dus ts }\end{array}$ & $\begin{array}{l}\text { S kylight w ell access; } \\
\text { Drilling or cutting walls or fals e ceilings or paneling; } \\
\text { Repairing cracks in the walls, scraping or s having for painting; } \\
\text { Ins tallation of lines of electrical or telephone or internet cable in } \\
\text { wall; } \\
\text { Medium interventions on ventilation or hydraulic (final section) in } \\
\text { multiple environments that require less than } 30 \text { minutes. }\end{array}$ & MEDIUM \\
\hline $\begin{array}{l}\text { TYPE C } \\
\text { Interventions that generate } \\
\text { from a moderate to a high } \\
\text { amount of dus ts and require } \\
\text { demolition or removal of } \\
\text { fixed structures. }\end{array}$ & $\begin{array}{l}\text { Removing floor or wall coverings; } \\
\text { Partial recons truction of walls until scraping or shaving for plas ter } \\
\text { or painting; } \\
\text { Ins tallation of pipes of hydraulic ducts, of ventilation, of lines of } \\
\text { electrical or telephone or internet cable in ceiling or fals e ceiling; } \\
\text { Medium interventions on ventilation or hydraulic (final section) in } \\
\text { multiple environments that require } 30 \text { minutes up to } 1 \text { hour. }\end{array}$ & MEDIUM-HIGH \\
\hline $\begin{array}{l}\text { TYPE D } \\
\text { Notew orthy w ork on } \\
\text { demolition, recons truction } \\
\text { and renovation. }\end{array}$ & $\begin{array}{l}\text { Complete removal of floor or wall coverings or ceilings; } \\
\text { Complete recons truction of w alls until scraping or shaving for } \\
\text { plas ter or painting; } \\
\text { Complete ins tallation of pipes of hydraulic ducts, of ventilation, of } \\
\text { lines of electrical or telephone or internet cable; } \\
\text { Interventions on ventilation or hydraulic sys tem in multiple } \\
\text { environments that take over } 1 \text { hour to be completed. }\end{array}$ & $\mathrm{HIGH}$ \\
\hline
\end{tabular}


- Analysis of construction activities: Data on intended construction activities can be derived either from project plans or by analysis of the construction sequence with the help of the BIM. This is, however, a manual step which lays the foundations for the later annotation of the exported schematics. In that process, parameterization according to the type of work (drilling - associated with a certain level of noise, dust and acting as a vibration source) needs to be conducted.

- Analysis of daily routines: Work activities and their spatial occurrence need to be analyzed with the help of a formal process model (available e.g. in the case of hospitals), by observation (in-situ survey) or expert interviews. We use a simplified model where each localized work activity acts as a receiver for dust, noise and vibrations; tolerance levels regarding the specific type of work have to be parameterized and checked by the simulation.

- Import of schematics: The exported bitmaps are imported into our tool, one bitmap per floor. Technically, we are using NetLogo 3D (Blikstein et al. 2005) as a platform, which is a modelling environment featuring a 3D cellular automaton in which agents (particles) can be simulated. Walls and doors are mapped to cells which act as environment for the simulation (conducted by particles).

- Annotation of activities: The 3D cellular automaton is populated with construction site activities and activities of daily work: For each construction activity (e.g. wall removal), we leave a spatial pin which is furthermore attributed with time (start; duration) and type of effect (noise; dust; vibration; strength). These construction activities will later act as sources for the said effects. On the other hand, we localize work activities within the construction site, parameterized by their time (start; duration) and acceptable levels of noise, dust and vibration. All in all, the sum of annotations resembles a virtual project plan. A time slider allows one to see the succession of different activities (see Figure 2). The resulting action - namely the relocation of different work activities and the implementation of constraining measures (such as sound insulation) is currently not implemented in the tool. These two items are left for future work.

Simulation and Visualisation: The construction activities (sources of adverse effects) and work activities (receivers of these effects) are simulated as shown in Figure 3: For each effect, we instantiate a particle that represents a sound wave, dust particle or vibration wave. The cell environment acts as a guide and constraint for these particles (e.g. air flow field in the case of dust). The effects of these particles can be observed visually (particles crossing into rooms where work activities occur) but can also be recorded in the work activity markers, which serve as receptors.

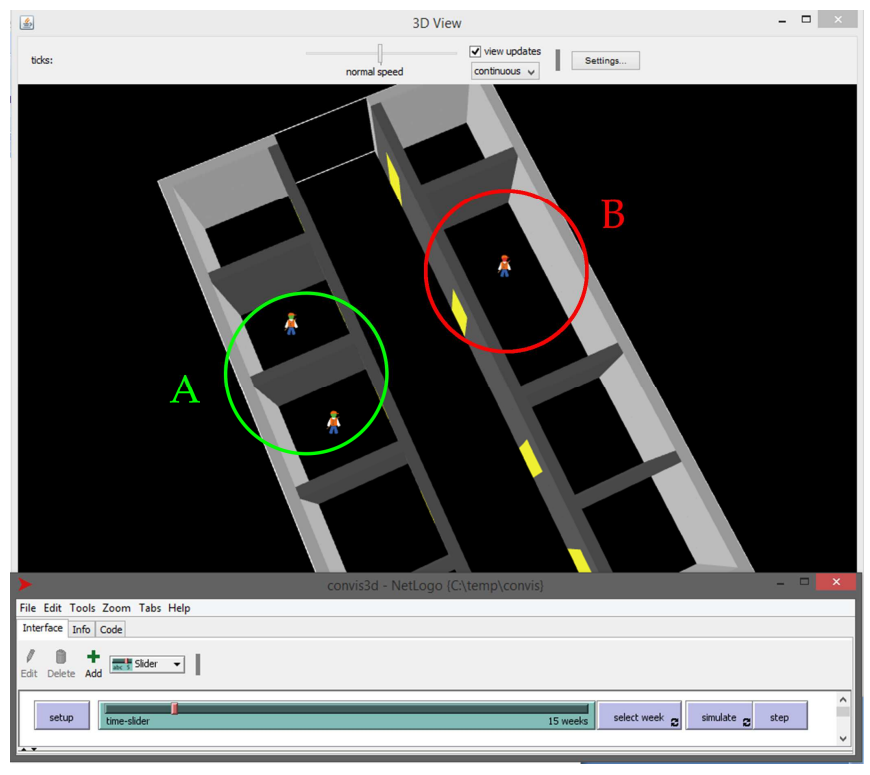

Figure 2: setting operation and construction activities (2 operation activities ${ }^{[\mathrm{A}]}$ and 1 construction site activity $\left.{ }^{[\mathrm{B}]}\right)$

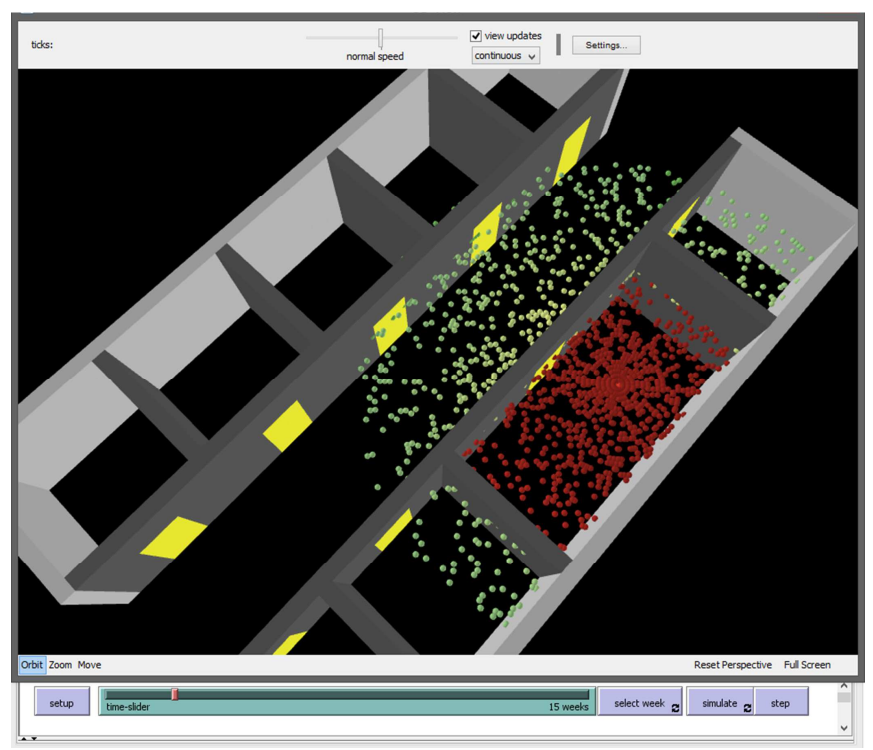

Figure 3: simulation of the noise impact of a construction site activity

\section{Prototype}

Our prototype was tested with a generic inpatient ward layout (individual rooms of $3 \times 3 \mathrm{~m}$; larger rooms of double that size; see again Figure 3), where each cell within our model has $0 . \dot{3} \mathrm{~m}$. Following that we tested with a similar ward of the Lower Austrian clinic Wiener Neustadt ( 826 beds) using the same cell resolution. The prototype in its current state allows

- $\quad$ to insert and edit different kinds of construction site and work activities, setting some parameters (e.g. start time, duration) as described in section 'Methodology'; 
- through simulation, one may monitor which area of the hospital is affected by construction site activities through time; one may also check which of the hospital activities are affected by which adverse effects

We are still implementing the ability to insert and set different kinds of construction site interventions (noise insulation etc.) and the ability to relocate work activities. These two features are left for future work, together with an in-depth description of the (cell-/particle-based) simulation models used.

\section{Conclusions}

We have worked on a tool that shows the effects of construction activities (noise, dust, vibrations) on daily operation (work activities) within complex building. The tool can be used for scheduling of construction activities such that an uninterrupted operation during refurbishment is possible. The intended audience is twofold: We support both operation management (e.g. business organisation, facility management) as well as construction professionals (scheduling of planned work items).

As future work, we seek to include the relocation of work activities and implementation of construction interventions (e.g. sound insulation). After this is done, we will move from our incubation environment (NetLogo 3D) into a Game Engine (Unity 3D) so as to improve the visual appearance and speed of our tool.

\section{References}

Zhang, S., Teizer, J., Lee, J.K., Eastman, C.M., and Venugopal, M. (2013), Building Information Modeling (BIM) and Safety: Automatic Safety Checking of Construction Models and Schedules, Automation in Construction, 29, pp. 183-195.

Azhar, S. (2011) Building Information Modeling (BIM): Trends, Benefits, Risks, and Challenges for the AEC Industry, Journal of Leadership and Management in Engineering, 11(3), pp. 241252.

D'Alessandro, D., Mura, I., and Vescia, N. (2007) Recommendations for the risk management of hospital yard: international guidelines, Proceedings of 34th Course - Building Yards in Hospital, Erice (TP), Italy, pp. 107- 123.

UNI EN ISO 11690-1 : 1996, Acoustics - Recommended practice for the design of low-noise workplaces containing machinery - Part 1: Noise control strategies.

CFR 291926.55 [Code of U.S. Federal Regulations Title 29, part 1926 "Safety and Health Regulations for Construction", subpart D "Occupational Health and Environmental Controls", standard number 1926.55 " Gases, vapors, fumes, dusts, and mists".

ISO 4866: 2010, Mechanical vibration and shock - Vibration of fixed structures - Guidelines for the measurement of vibrations and evaluation of their effects on structures.
Castro, D., Simões, H., Figureido, J.P., Tavares, Ó., Braga, H., Negrão, M,. Gonçalves, R., Bizarro, V., Ferreira, D., and Ferreira, A. (2013) Determination of noise level in the intensive care unit of Coimbra Hospital and University Center, International Symposium on Occupational Safety and HygieneSHO2013, Guimarães (Portugal), pp. 425-430.

Choiniere D.B. (2010) The effects of hospital noise, Nursing administrator quarterly, 34(4), 327-333.

Uguccioni, G. (2005), L'evoluzione della tecnologia impiantistica al servizio degli edifici ospedalieri', XXXII Convegno ANIMP OICE - UAMI, Rimini, pp. 33-34.

Moscato, U., La Pietra, L., and Ricciardi, G. (2007) Nonviable particles and hospital yards, Proceedings of 34th Course Building Yards in Hospital, Erice (TP), Italy, pp. 173-191

Trento, A., Fioravanti, A., and Rossini, F. (2014) Health and Safety Design by means of a Systemic Approach, in Proceedings of eCAADe 2014, pp. 633-642.

Linehan, M., and Andress, B. (2013), Medical equipment and BIM, HFM-Magazine, pp.11.

Blikstein, P., Abrahamson, D. and Wilensky, U. (2005), NetLogo: Where We Are, Where We're Going, Proceedings of the annual meeting of Interaction Design and Children, 23, 2 pages. 